\title{
A 3D analysis of crack-front shape of asymmetric repaired aluminum panels with composite patches
}

\author{
El Hadj Besseghier, Abdelkader Djebli, Mostefa Bendouba, Abdelghani Baltach, Abdelkrim \\ Aid. \\ Laboratory of Quantum Physics of Matter and Mathematical Modeling (LPQ3M), University of Mascara, Mascara 29000, \\ Algeria. \\ besseghier.badj@outlook.fr,djebliabdelkader@univ-mascara.dv,bendoubamos@yahoo.fr,baltachabdelghani@yahoo.fr, \\ aid_abdelkrim@gmail.com.
}

\begin{abstract}
Through this study, a numerical simulation based on 3D in order to investigate the effect of crack-front shape on the stress intensity factor and fatigue crack growth behavior of center cracked aluminum plate repaired asymmetrically with bonded composite patch. Consequently, skew degree it is a significant effect on stress intensity factor (SIF) distribution along the crack front in thick panels more than in thin panels. Moreover, fatigue life was calculated using different averaged stress intensity factor of patched panel determined from uniform crack front model and skew crack front model obtained from FEM and when comparing fatigue life values obtained from the finite element model with experimental values were shown a good agreement.
\end{abstract}

KEYwORDS. Patch repair; Stress intensity factor; Aluminum alloy; Fatigue; Crack front.

\section{OPEN ACCESS}

Citation: Besseghier, E.H., Djebli, A., Bendouba, M., Baltach, A., Aid, A., A 3D analysis of crack-front shape of asymmetric repaired aluminum panels with composite patches, Frattura ed Integrità Strutturale, 49 (2019) 547-556.

Received: 26.02 .2019

Accepted: 05.05.2019

Published: 01.07.2019

Copyright: (C) 2019 This is an open access article under the terms of the CC-BY 4.0, which permits unrestricted use, distribution, and reproduction in any medium, provided the original author and source are credited.

\section{INTRODUCTION}

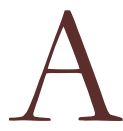

mong the methods of repairing damaged structures, bonding a composite patch is currently the most used. In particular, composite patch repair has shown its effectiveness in the field of aeronautics and maritime structures [1-2]. According to research, most studies address the problem of shape optimization, i.e the surface and the thickness of the patch [3-10]. Without omitting the effect of the parameters related to the adhesive such as the thickness and the type of the glue that have provoked several searches as for example in [11-15]. Allan Baker initially developed the technique of bonding a composite patch in a cracked structure in the late 1970s. This technique appeared to be an advantageous alternative to the more conventional techniques of repair, by riveting or welding metallic structures. Indeed, the bonding of a composite patch to the damaged structure significantly reduces the stress field on the damaged area. That leads to improve the structural strength and the extension of the lifetime of the structure under stress [16-17], without 
introducing a new hole or changing the microstructure of the material. In fact, there are two patch repair techniques, namely, simple patch repair (asymmetric repair) and double side patch repair (symmetric repair) [16-19]. Generally, it is the double patch that is preferable, because of the deflection effects that the simple patch introduces into the charged structure [20]. Regardless of the type of repair (symmetrical or asymmetrical), parameters such as thickness, surface area, number of layers, fiber orientation and patch shape remain the most studied for their interdependent influence on repair efficiency. In this context, Ramji \& all carried out a comparative study in [16]. These authors studied several forms of patch and concluded that an extended octagonal patch has better performance for stress intensity factor reduction. Recently, Bachir Bouiadjra \& all concluded in [7] that a trapezoidal form is more powerful than a rectangular form. Furthermore, in [10], it was concluded that a butterfly shape with a suitable dimensions is more efficient than the rectangular shape. For the number of layer and the thickness of the patch, H. Hosseini and colleagues in [21] concluded that the performance of the patch is proportionately improved by increasing the number of layers and reducing the thickness of the plate. Furthermore, [22] established that increasing the life of the repaired plate is related to increasing the thickness of the patch. Also for the type of composite used in the repair, H. Hosseini and co-workers in [23] found that, for a $45^{\circ}$ inclined crack in a thick aluminum panel repaired by an asymmetric glass / epoxy patch, the lifetime during the crack propagation is significantly improved. Among the positive effects on the repair, [24] studied the effect of overload during the fatigue test. As a result, it was found that overloading extends the service life of the repaired structure.

Despite a large number of published researches on this topic, to our knowledge, few of them consider the value of the stress intensity factor to be used for estimating the lifetime of repaired structures. Indeed, D. C. Seo and J. J. Lee in [25] experimentally proved that the crack front is not always a straight line when the crack is propagated. These latter concluded that the stress intensity factor of thick specimen showed a large variation through thickness direction. Moreover, Woo-Yong Lee and Jung-Ju Lee in [26] stated that the stress intensity factor (SIF) calculated at the crack tip is much influenced by crack front shape. Consequently, they proposed to predict the actual crack front shape evolution and take it into account for the accurate analysis of fatigue behavior. This was confirmed later by H. Hosseini et al. in [27] and recently in [28], where it was noted that the crack growths non-uniformly from its initial location through the thickness of the repaired panel and the maximum crack length occur at un-patched surface of the panels.

In this study, for the accurate investigation of fatigue crack growth behavior, a consideration is taken for the crack front inclined in its plan from the patched toward un-patched side by various angles. This is done to simulate the experimental fatigue crack-growth behavior in mode-I failure and examine the SIF's distribution along the crack front within centrally cracked aluminum panels. Moreover, trying to understand the physic of the crack growth difference between patched and un-patched side in two different panels thick and thin.

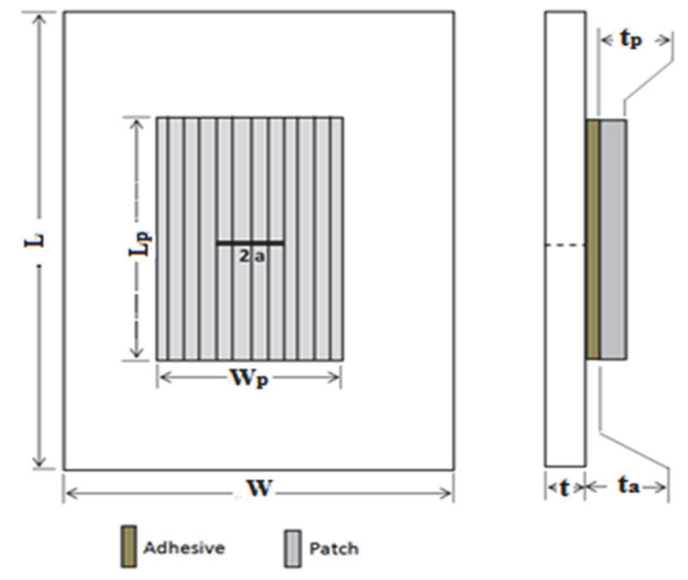

Figure 1 Geometrical model of the repaired central cracked specimen.

\section{GEOMETRIES AND MECHANICAL PROPERTIES OF THE MODEL}

$\mathrm{F}$ ig. 1 shows the basic geometry of the cracked structure considered in this study. This model is adapted from that proposed in [21]. The aluminum alloy plate 2014-T3 has dimensions of $100 \times 50 \mathrm{~mm} 2$ with two different thicknesses, namely 2.29 and $6.35 \mathrm{~mm}$. the plates contain an initial crack length of $2 \mathrm{a}=10 \mathrm{~mm}$ and perpendicular to the loading axis (Fig. 1). Table 1 summarizes the dimensions of the plate, the patch and the adhesive. Mechanical 
properties of the 2024-T3 aluminum alloy plate, the glass/epoxy composite patch and the FM-77 adhesive are given in table 2 .

\begin{tabular}{cccc}
\hline Material & Aluminum panel & Patch & Adhesive \\
L (mm) & 100 & 40 & 40 \\
W (mm) & 50 & 35 & 35 \\
$\mathrm{t}(\mathrm{mm})$ & 2.29 and 6.35 & 1.44 & 0.1 \\
\hline
\end{tabular}

Table 1: Dimensions of the panel, adhesive layer and patch.

\begin{tabular}{cccccc}
\hline Material & $\mathrm{E} 1(\mathrm{GPa})$ & $\mathrm{E} 2, \mathrm{E} 3(\mathrm{GPa})$ & $\nu 12, \nu 13, \nu 23$ & $\begin{array}{c}\mathrm{G} 12, \mathrm{G} 13 \\
(\mathrm{GPa})\end{array}$ & $\mathrm{G} 23(\mathrm{GPa})$ \\
$\begin{array}{c}\text { Aluminum } \\
\text { (2014-T3) }\end{array}$ & 71.3 & - & 0.33 & - & - \\
Glass/epoxy & 50 & 14.5 & 0.33 & 2.56 & 2.24 \\
Adhesive(FM77) & 1.89 & - & 0.33 & - & - \\
\hline
\end{tabular}

Table 2: Materials properties.

The objective of this work is to analyze the effect of the inclination of the crack front in its plane. For this purpose, the crack line is inclined from the patched side toward the un-patched side by different angles $\Theta=0^{\circ}, 15^{\circ}, 30^{\circ}, 45^{\circ}$ and $60^{\circ}$ respectively (Fig. 2.a). Fig. 2.b shows the different inclinations of the crack front, where the mesh refinment indicates the front of the crack and the immediate adjacent region in the plane of the thickness. Then to compare the stress intensity distribution between two different thickness panels, i.e. thin $(2.29 \mathrm{~mm})$ and thick $(6.35 \mathrm{~mm})$.

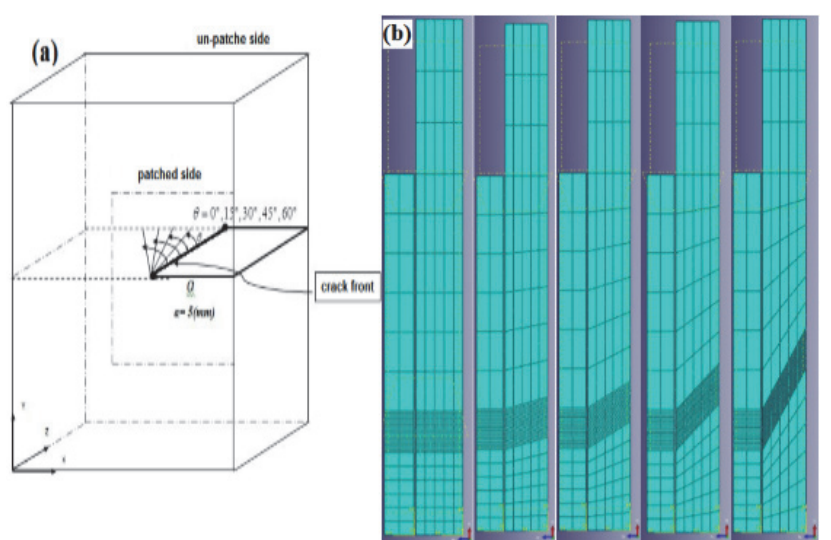

Figure 2 (a) skew crack front. (b) Finite element model showing the crack front configuration

\section{NUMERICAL MODELING AND BOUNDARY CONDITIONS}

he model was solicited by applying a cyclic load to the upper edge in the y-direction with a lower edge embedding. So, the plate is subjected to a maximum stress $\sigma=118 \mathrm{MPa}$ with a load ratio of $\mathrm{R}=0.05$.

The analysis was carried out using Abaqus 6.13 software. A three-dimensional finite element method with automatic meshing was carried out on the structure using 8-nodes brick elements and refinement of the mesh was created in the vicinity of the crack tips as shown in figures 3.c. The composite patches ply orientation is parallel to the loading axis. So, as geometry and loading conditions are symmetrical, only one quarter of the specimens were simulated. Due to its simplicity, Paris law is usually used to predict the fatigue life, which can be expressed as [21]:

$$
\frac{d a}{d N}=C(\Delta K)^{m}
$$


where $C$ and $m$ are properties constant for a material regrouped in tab.3, $\Delta \mathrm{K}=\mathrm{K}_{\max }-\mathrm{K}_{\min }$ is the SIF range, $\mathrm{N}$ is number of cycles, a is crack length and da is change in crack length.

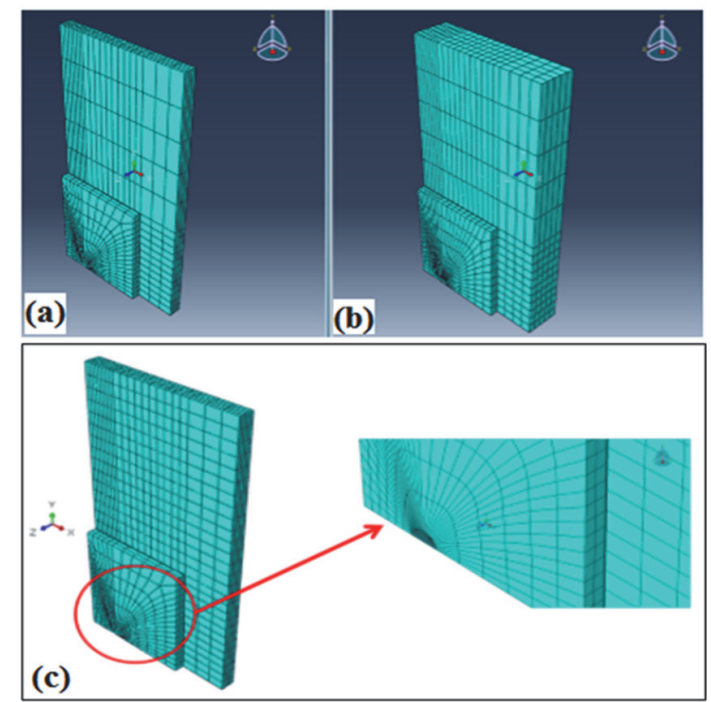

Figure 3 Finite element model mesh of the repaired plate. (a) $t=2.29 \mathrm{~mm}$, (b) $t=6.35 \mathrm{~mm}$ and (c) near crack mesh refinement.

\begin{tabular}{cc}
\hline Plate thickness $2.29(\mathrm{~mm})$ & Plate thickness $6.35(\mathrm{~mm})$ \\
$\mathrm{m}=3.2828$ & $\mathrm{~m}=4.224$ \\
$\mathrm{C}=3.63 \mathrm{e}-13$ & $\mathrm{C}=1.51 \mathrm{e}-15$ \\
\hline
\end{tabular}

Table 3: Material constants in Paris law for aluminum plates [21].

The adopted method was to evaluate SIFs with ABAQUS using J-integral. The energy approach states that fracture will occur when the energy release rate, reaches a critical value $G_{c}$, and is consistent with the idea that failure occurs when the SIF in mode I, $\mathrm{K}_{\mathrm{I}}$, reaches a critical value, called the fracture toughness $\left(\mathrm{K}_{\mathrm{IC}}\right)$. For linear elastic material, J (equivalent to $\mathrm{G})$ is related to the SIF by [29]:

$$
J=G_{\mathrm{I}}+G_{\mathrm{II}}+G_{\mathrm{III}}=\frac{1}{E^{*}}\left(K_{\mathrm{I}}^{2}+K_{\mathrm{II}}^{2}\right)+\frac{1}{2 G^{*}} K_{\mathrm{III}}^{2}
$$

where I, II and III denotes the modes of fracture, and $\mathrm{E}^{*}=\mathrm{E} /\left(1-v^{2}\right)$ for plane strain case (3D configuration). The Jintegral in pure mode I loading condition, can then be correlated to KI using the relation:

$$
K_{I}=\sqrt{\frac{E J}{1-v^{2}}}
$$

where E is Young's modulus and $v$ is the Poisson's ratio. If an arbitrary contour is considered as illustrated in Fig.4, the J-integral is given by:

$$
J=\int_{\Gamma} w d y-T_{i} \frac{\partial u_{i}}{\partial x} d s
$$

where $w$ is the strain energy density, $T_{i}$ are components of the traction vector, $u_{i}$ are the displacement vector components, and ds is a length increment along the contour $T$. The strain energy is defined as: 


$$
w=\int_{0}^{\varepsilon_{i j}} \sigma_{i j} d \varepsilon_{i j}
$$

where, $\sigma_{\mathrm{ij}}$ and $\varepsilon_{\mathrm{ij}}$ are the stress and strain tensors, respectively. The traction is a stress vector normal to the contour. To evaluate these integrals, ABAQUS defines the domain in terms of rings of elements surrounding the crack tip.

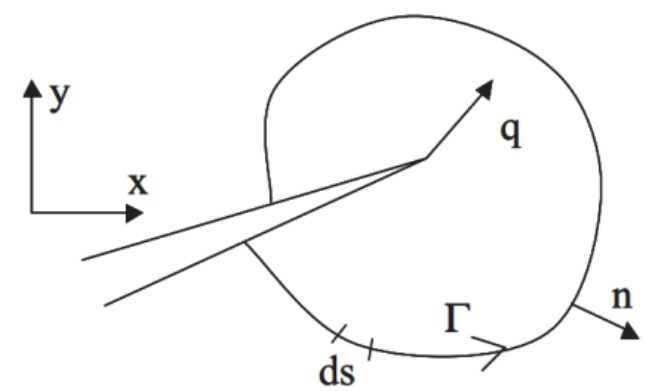

Figure 4: Definition of the J-integral: a contour integral along the path $\Gamma[y]$.

The Von-Mises stress used in the analysis of stress distribution along the crack front can be written in terms of stress components as [30]:

$$
\sigma_{V M}=\sqrt{\frac{\left(\sigma_{x x}-\sigma_{y y}\right)^{2}+\left(\sigma_{y y}-\sigma_{z z}\right)^{2}\left(\sigma_{z z}-\sigma_{x x}\right)^{2}+6\left(\tau_{x y}{ }^{2}+\tau_{y z}{ }^{2}+\tau_{z x}{ }^{2}\right)}{2}}
$$

where, $\sigma_{x x}, \sigma_{y y}$ and $\sigma_{z z}$ are the normal stresses according to $\mathrm{x}, \mathrm{y}$ and $z$ direction respectively and $\tau_{x y}, \tau_{y z}$ and $\tau_{z x}$ are shear stresses in the $y z, x z$ and xy planes respectively (Fig. 5).

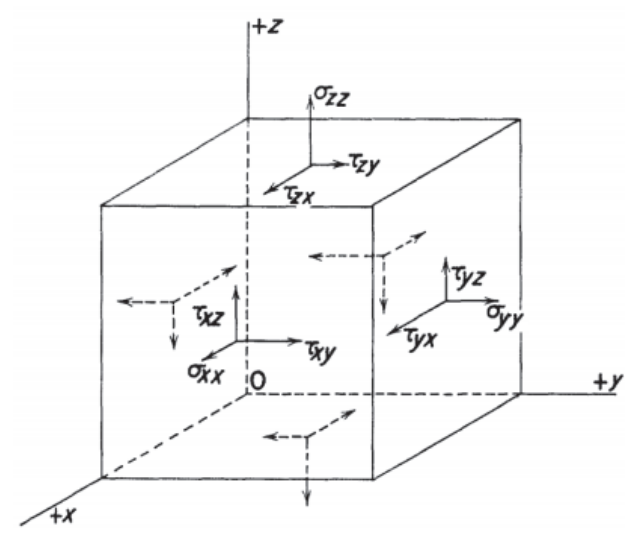

Figure 5: Stresses on a cubical element in equilibrium

\section{VALIDATION OF THE MODEL}

he validation of the present model is presented in fig.6.a and 6.b, where a comparison with the results of Hossieni \& all [21] is made. The figures show a comparison of the fatigue life of thin and thick panels respectively. Moreover, it can be seen from the figures that present results are in good agreement with the literature. Figure gives the fatigue life of plate after repair. 

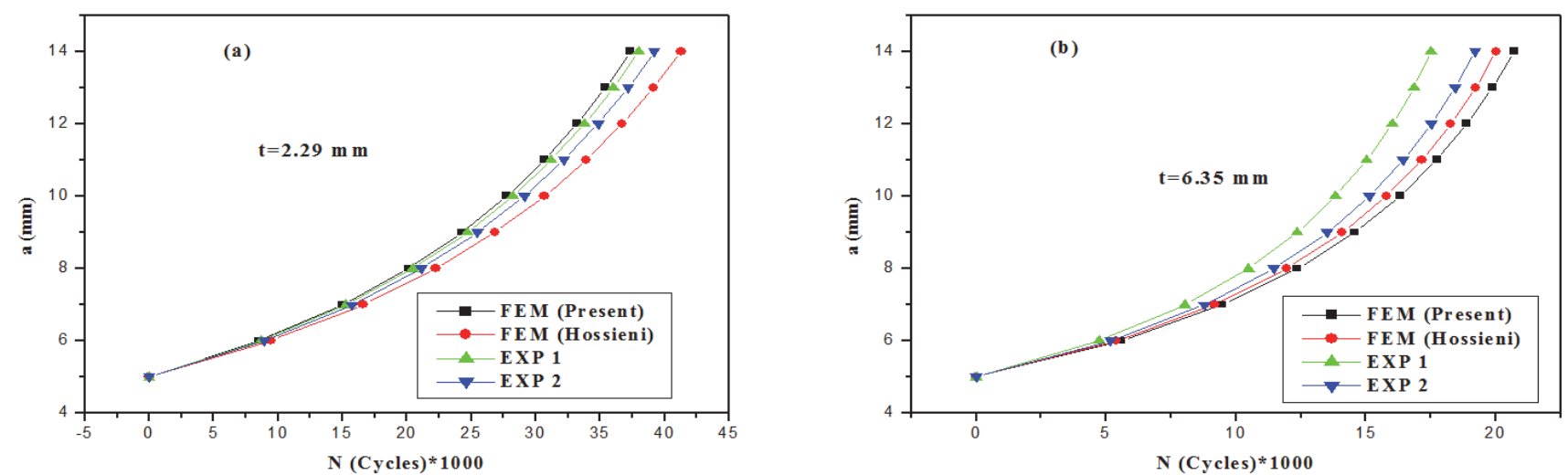

Figure 6: Comparisons of finite element results with experimental data for the fatigue life of repaired panels. (a) $\mathrm{t}=2.29 \mathrm{~mm}$ (b) $\mathrm{t}=6.35 \mathrm{~mm}$.

\section{RESULTS AND DISCUSSION}

$\mathrm{F}$ igs 7.a and 7.b present the distribution of von-mises stresses in thin and thick repaired aluminum plates respectively. The crack length is taken to be $2 \mathrm{a}=10 \mathrm{~mm}$. From fig 7.a, a non uniform distribution along the crack front can be observed. In fact, the stress transfer between the repaired plate and the patches mainly occurs in the patched side of the plate. The stress at the crack tip in the patched side of the plate is much smaller than that in the unpatched side of the plate, which accounts for SIF variation in thickness direction of the aluminum plate. Moreover, comparing the crack tip stresses distribution between figs7.a and 7.b, one can also observe that with the help of the patches, the stress at the crack tip in thin repaired plate is much smaller than that in the thicker one. This accounts for the significant SIF's difference between thin and thick plates.

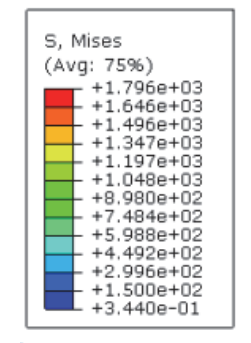

(a)
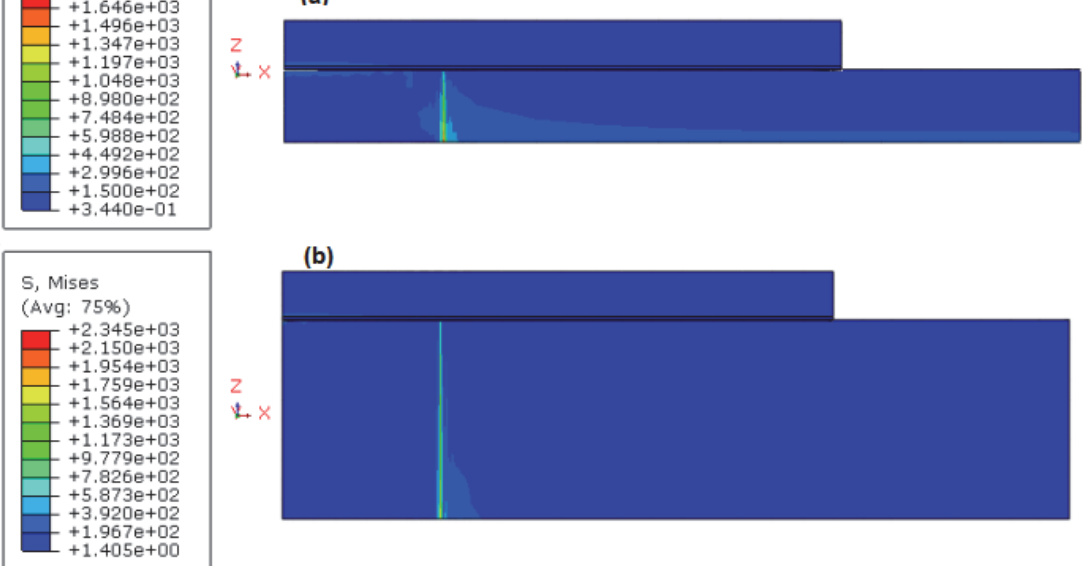

(b)

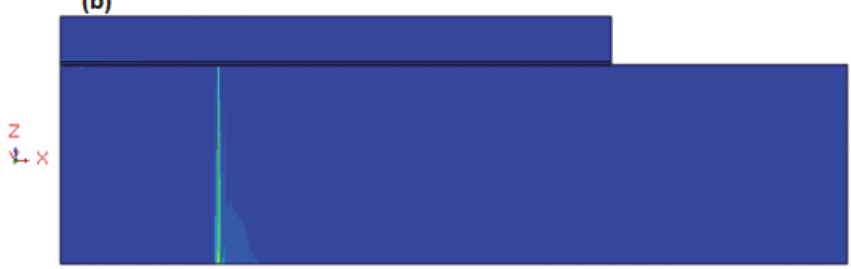

Figure 7: Distribution of the Von-Mises stresses across the crack front for the repaired plate. (a) $t=2.29 \mathrm{~mm}$; (b) $t=6.35 \mathrm{~mm}$.

Fig. 8 shows that the change in maximum values of von-mises stresses (red zone in fig) is with growth of the crack where this value is shifted from the free side toward the patched side and this applies to all panels, whether thin or thick. Accordingly, this finding will be highlighted, hereinafter by the stress intensity factor results in fig 9.a and 9.b.

Figures 9.a and 9.b shows the distribution of stress intensity factor along the crack front. It is noted through the curves trend that the maximum value of SIF is shifted from the free side of the plate towards the patched side. This suggests a cascade growth of the crack, obviously starting from the free surface going toward the patched surface. A differed of this behavior can be noted between the thin and the thick plates. Effectively, the maximum value in fig 8.a is resulted for the angle $\Theta=0^{\circ}$ curve and the last point in crack front in the free side of the plate. This maximum value is in no case 
exceeded for other configurations (fig. 8.a). On the other side, fig. 8.b shows that the maximum value of the stress intensity factor increases with the growth of the angle and is located inside the front of the crack.
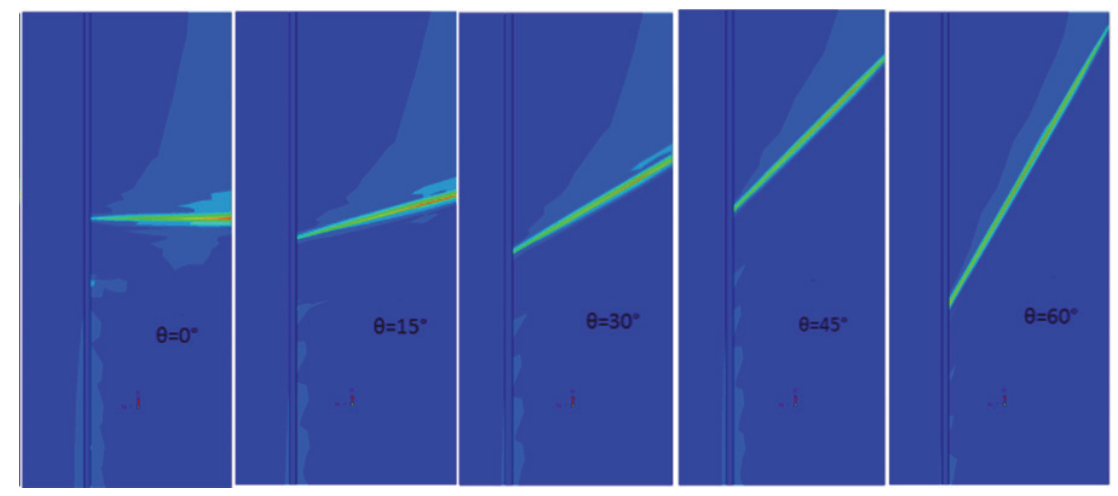

Figure 8: Distribution of the Von-Mises stresses $(\mathrm{MPa})$ in skew crack front.
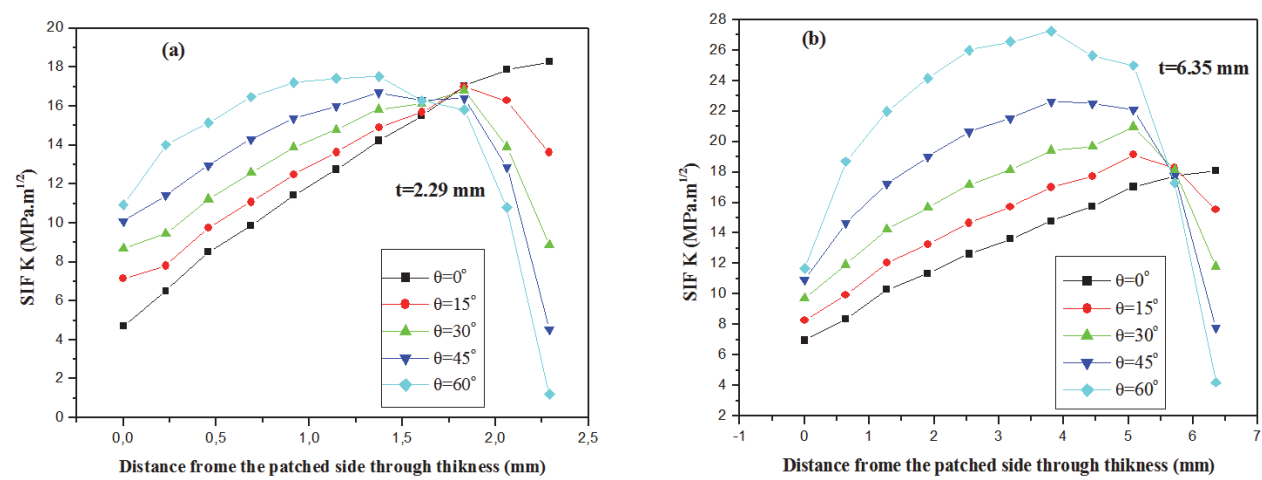

Figure 9: Stress intensity factors along skewed crack front for different thickness. (a) $t=2.29 \mathrm{~mm}$ (b) $t=6.35 \mathrm{~mm}$.

Consequently, this explains the crack shape in the fig 10.a where it is clearly shown that the maximum length of the crack appears in last point crack front of the free side of the panel and this makes it compatible with stress intensity factor distribution results.
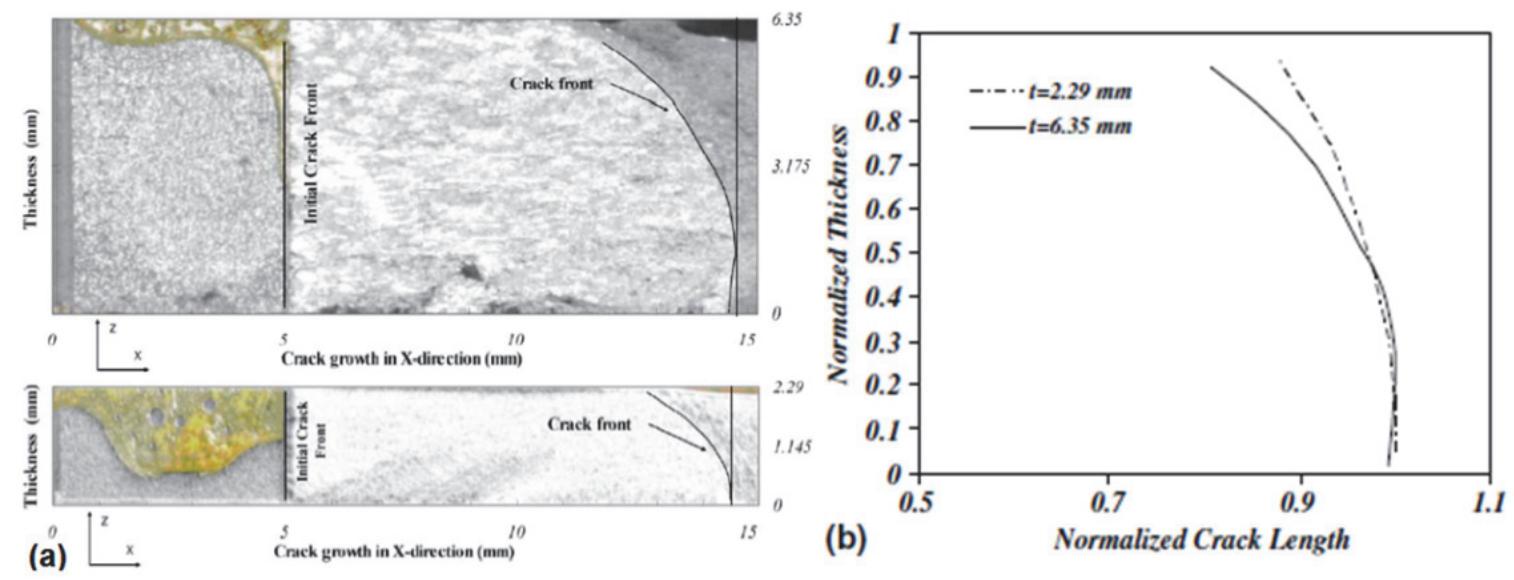

Figure 10 (a) Crack-front shape obtained from fatigue crack propagation of repaired plates (b) Comparison of normalized crack-front shapes between repaired panels with $2.29 \mathrm{~mm}$ and $6.35 \mathrm{~mm}$ thickness [27].

Fig. 9 shows the distribution of the stress intensity along the crack front for the thick panels where it can be observed a shifted of maximum value from the free side of the plate towards the patched side. Accordingly, the maximum value is 
obtained for the angle $\theta=60^{\circ}$ and located at approximately $60 \%$ (fig. 9.b) of the thickness from the patched side to the free side and this also makes it compatible with the shape of the crack in fig10.a. Fig. 10.a also shows the maximum length of crack whose position exactly corresponds to the position for the maximum value of stress intensity factor.

Fig.10.b compares the normalized crack-front shapes between repaired plates with $2.29 \mathrm{~mm}$ and $6.35 \mathrm{~mm}$ thickness. As can be seen in the figure, the difference between the maximum length crack positions confirms the current results. Thus, it is useful to give a precise prediction of the crack behavior and to identify the adequate value of the stress intensity factor for an accurate estimate of the lifetime of the patch-repaired structure and this for the two thicknesses studied in this work.

In this respect, Fig.11 shows a comparison between average of the stress intensity factors versus the crack front inclination for thin and thick panels. Incontestably, the obtained results indicate horizontal monotony of the average stress intensity factors for a thin panel. Accordingly, one can suggest that the ideal choice for the calculation of the crack propagation is the average of the SIF's values along the crack front. This will be confirmed, hereinafter through the analyzed fatigue life results. Conversely, the curve of the thick panel $(t=6.35 \mathrm{~mm})$ shows a change of the average stress intensity factor when the skew changed. Here, the averaged SIF icreases with the increase of the skew angle.



Figure 11: Average stress intensity factors versus angle inclination in the crack plane for different thickness

Figs. 12.a and 12.b show the comparison of fatigue life between experimental results and FEM results obtained from using different averaged stress intensity factor, namelly maximum value in the thickness direction (K.max), average all values in the thickness direction (avg-all), mid-point value in the thickness direction (K.mid), root mean square value of all values (avg-K.rms), average all values from patched side to mid-point (avg-H.P.S), average all values from unpatched side to mid-point (avg-H.un-P.S), average all values except the values of both side element in the thickness direction (avg9.mid).
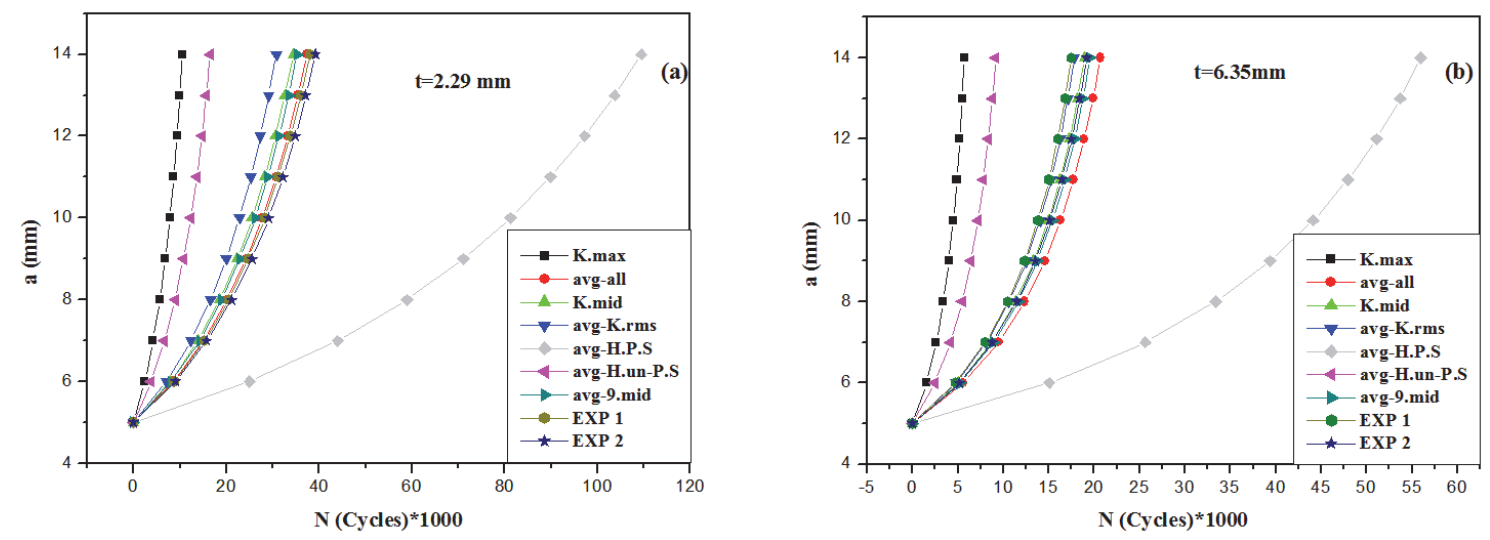

Figure 12: Comparison of fatigue life between experimental results and predicted values using averaged FEM results: (a) $\mathrm{t}=2.29 \mathrm{~mm}$ (b) $\mathrm{t}=6.35 \mathrm{~mm}$. 
As expected above by analyzing the distribution of stress intensity factors, Fig. 12.a shows that the fatigue lifetime obtained from using of the stress intensity factor (avg-all) and to a lesser extent the results obtained from using the (avg9.mid) , (K.mid) and (avg-K.rms) respectively, gives a precise results for the case of thin repaired plates .This is evident through a good agreement of FEM curve results obtained from (avg-all) with experimental curve.

On another side, Fig.12.b shows that the values obtained from the root mean square stress intensity factor (avg-K.rms) and to a lesser extent obtained from the (K.mid), (avg-9 .mid) and (avg-all), respectively gives precise results for the case of the thick repaired plates. this is evidenced by the good agreement of the numerically obtained lifetimes with those obtained experimentally.

\section{CONCLUSION}

his study focused on the fatigue crack growth behavior of center cracked aluminum plate repaired asymmetrically with bonded composite patch. The analysis led to the following conclusions:

- The stress at the crack tip in the patched side of the plate is much smaller than that in the un-patched side of the plate.

- The maximum length of crack whose position exactly corresponds to the position for the maximum value of stress intensity factor.

- The crack front shape differs between the thin and thick plates.

- Reliance on the stress average all (avg-all) in the calculate the fatigue life of the thin plates repaired asymmetrically. Showed excellent accuracy compared with experimentally reverse thick plates which the stress root mean square (K.rms).

\section{REFERENCES}

[1] Baker, A.A., Rose, L.R.F., Jones, R. (2002). Advances in the bonded composite repair of metallic aircraft structure, Killington, Elsevier Publications.

[2] Bianchi, R. W., Kwon, Y. W., Alley, E. S. (2019). Composite Patch Repair for Underwater Aluminum Structures, Journal of Offshore Mechanics and Arctic Engineering, 141(6), p. 064501. DOI: 10.1115/1.4042940.

[3] Umamaheswar, T.V.R.S., Ripudaman, S. (1999). Modelling of a patch repair to a thin cracked sheet, Eng Fract Mech., 62(2-3), pp. 267-289. DOI: org/10.1016/S0013-7944(98)00088-5.

[4] Mahadesh, K.A., Hakeem, S.A. (2000). Optimum design of symmetric composite patch repair to center cracked metallic sheet, Compos Struct. 49(3), pp. 285-292. DOI:org/10.1016/S0263-8223(00)00005-2.

[5] Brighenti, R. (2007). Patch repair design optimization for fracture and fatigue improvements of cracked plates. Solids Struct. 44(3-4), pp. 1115-1131. DOI: org/10.1016/j.ijsolstr.2006.06.006.

[6] Rachid, M., Serier, B., Bachir Bouiadjra, B., Belhouari, M. (2012). Numerical analysis of the patch shape effects on the performances of bonded composite repair in aircraft structures, Compos B: Eng. 43(2), pp. 391-397. DOI: org/10.1016/j.compositesb.2011.08.047.

[7] Bachir Bouiadjra, B., Fari Bouanani, M., Albedah, A., Benyahia, F., Es-Saheb M., (2011). Comparison between rectangular and trapezoidal bonded composite repairs in aircraft structures: a numerical analysis, Mater Des. 32(6), pp. 3161-3166. DOI: org/10.1016/j.matdes.2011.02.053.

[8] Kashfuddoja, M., Ramji, M. (2014). Design of optimum patch shape and size for bonded repair on damaged Carbon fibre reinforced polymer panels, Mater Des. 54, pp. 174-183. DOI: org/10.1016/j.matdes.2013.08.043.

[9] Soutis, C., Hu, F.Z. (1997). Design and performance of bonded patch repairs of composite structures, Proc Inst Mech Eng G: Aerospace Eng. 211(4), pp. 263-271. DOI:org/10.1243/0954410971532668.

[10] Besseghier, E.H., Djebli, A., Bendouba, M., Aid, A. (2017). Effect of Patch Shape on the Repair Efficiency of a Cracked Aluminum Panel, Materials and Engineering Structures, 4, pp. 225-233.

[11] Shiuh-Chuan, H., Chao, M.N. (2011). Adhesively bonded patch repair of composite laminates, Adhes Sci Technol. 25(18), pp. 2569-2585. DOI: org/10.1163/016942411X580234.

[12] Turaga, V.R.S., Ripudiman, (1999). Modeling of patch repairs to a thin cracked sheet. Engn. Fract. Mec. 74, pp. 431443.

[13] Cheng, P., Xiao-Jing, G., Hearn, D., Aivazzadeh, S. (2011). Tensile behaviour of patch- repaired CFRP laminates, Compos Struct. 93(2), pp. 582-589. DOI: org/10.1016/j.compstruct.2010.08.021. 
[14] Liu, X., Wang, G. (2007). Progressive failure analysis of bonded composite repairs. Compos Struct. 81(3), pp. 331 340. DOI: org/10.1016/j.compstruct.2006.08.024

[15] Albedah, A., Bouiadjra, B. B., Benyahia, F., Mohammed, S. M. K. (2018). Effects of adhesive disbond and thermal residual stresses on the fatigue life of cracked 2024-T3 aluminum panels repaired with a composite patch. International Journal of Adhesion and Adhesives, 87, pp. 22-30. DOI: 10.1016/j.ijadhadh.2018.09.004

[16] Ramji, M., Srilakshmi, R., Bhanu Prakash, M. (2013), Towards optimization of patch shape on the performance of bonded composite repair using FEM. Composites: Part B. 45(1), pp. 710-720.

DOI: 10.1016/j.compositesb.2012.07.049.

[17] Belhouari, M., Bachir Bouiadjra, B., Megueni, A., Kaddouri, K. (2004). Comparison of double and single bonded repairs to symmetric composite structures: a numerical analysis, Composite Structures. 65(1), pp. 47-53. DOI: 10.1016/j.compstruct.2003.10.005.

[18] Baltach, A., Aid, A., Djebli, A., Bouiedjra, B. B., Benhamena, A. (2017). Numerical Analysis of Asymmetrically Bonded Composite Patch Repair and Effect of In-Plane Skewed Crack Front on the SIF. Int. J. Eng. Res. Afr. 30, pp.11-22. DOI: 10.4028/www.scientific.net/JERA.30.11

[19] Makwana, A., Shaikh, A. A., Bakare, A. K., Saikrishna, C. (2018). 3D Numerical Investigation of Aluminum 2024-T3 Plate Repaired with Asymmetric and Symmetric Composite Patch. Materials Today: Proceedings, 5(11), pp. 2363823647. DOI: $10.1016 /$ j.matpr.2018.10.153.

[20] Duong, C.N., Wang, C.H. (2007). Composite repair, theory and design. Amsterdam, Elsevier Publications.

[21] Hosseini-Toudeshky, H., Mohammadi, B., Sadeghi, G, Daghyani, H.R. (2007). Numerical and experimental fatigue crack growth analysis in mode-I for repaired aluminum panels using composite material. Composites: Part A. 38(4), pp. 1141-1148. DOI: 10.1016/j.compositesa.2006.06.003.

[22] Hosseini-Toudeshky, H., Ghaffari, M.A., Mohammadi, B. (2012). Finite element fatigue propagation of induced cracks by stiffeners in repaired panels with composite patches, Compos Struct. 94(5), pp. 1771-1780. DOI: 10.1016/j.compstruct.2012.01.002.

[23] Hosseini-Toudeshky, H., Bakhshaneh, S. Mohammadi, B. Daghyani, H.R. (2006). Experimental investigations on fatigue crack growth of repaired thick aluminum panels in mixed-mode conditions, Composite Structures 75(1-4), pp. 437-443. DOI: 10.1016/j.compstruct.2006.04.021.

[24] Seriari, F. Z., Benachour, M., Benguediab, M. (2018). Fatigue crack growth of composite patch repaired Al-alloy plates under variable amplitude loading, Frattura ed Integrità Strutturale, 12(43), pp. 43-56. DOI: 10.3221/IGF-ESIS.43.03.

[25] Seo, D. C., Lee, J. J. (2002). Fatigue crack growth behavior of cracked aluminum plate repaired with composite patch, Composite Structures, 57(1-4), pp. 323-330. DOI: 10.1016/S0263-8223(02)00095-8.

[26] Lee, W.Y., Lee, J. J. (2004). Successive 3D FE analysis technique for characterization of fatigue crack growth behavior in composite repaired aluminum plate, Composite Structures, 66(1-4), pp. 513-520. DOI: $10.1016 /$ j.compstruct.2004.04.074.

[27] Hosseini-Toudeshky, H., Sadeghi, G., Daghyani, H.R. (2005). Experimental fatigue crack growth and crack-front shape analysis of asymmetric repaired aluminium panels with glass/epoxy composite patches, Composite Structures 71, pp. 401-406. DOI: 10.1016/j.compstruct.2005.09.032.

[28] Hosseini-Toudeshky, H., Ghaffari, M.A., Mohammadi, B. (2011). Fatigue propagation of induced cracks by stiffeners in repaired panels with composite patches, Procedia Engineering, 10, pp. 3285-3290. DOI: 10.1016/j.proeng.2011.04.542.

[29] Duó, P., Nowell, D. (2003). The use of Abaqus for stress intensity factors evaluation: Comparison with the distributed dislocation method and other numerical approaches. UK abaqus user group conference.

[30] Nies, A. (2016). A critical analysis of the Mises stress criterion used in frequency domain fatigue life prediction, Frattura ed Integrità Strutturale, 38, pp. 177-183. DOI: 10.3221/IGF-ESIS.38.24. 